\title{
Sunitinib in patients with metastatic renal cell carcinoma: Birmingham experience
}

\author{
JAWAHER ANSARI ${ }^{1,3}$, ARFEEN FATIMA $^{1}$, KIERAN FERNANDO ${ }^{1}$, \\ STUART COLLINS ${ }^{2}$, NICHOLAS D. JAMES ${ }^{1}$ and EMILIO PORFIRI ${ }^{1}$ \\ ${ }^{1}$ University Hospital Birmingham NHS Trust; ${ }^{2}$ Cancer Research UK Clinical Trials Unit, \\ Institute for Cancer Studies, University of Birmingham, Edgbaston, Birmingham B15 2TH, UK
}

Received January 22, 2010; Accepted March 15, 2010

DOI: $10.3892 /$ or_00000886

\begin{abstract}
Sunitinib is a novel, multi-targeted receptor tyrosine kinase inhibitor, which has demonstrated evidence of improved survival when compared to interferon (IFN)- $\alpha$ in patients with metastatic renal cell carcinoma (RCC). Recently published National Institute for Health and Clinical Excellence guidance recommends sunitinib as a first-line treatment option for patients with advanced and/or metastatic RCC. We assessed the efficacy and toxicity of sunitinib in an unselected group of patients with metastatic RCC, and compared outcomes in clinical practice with published clinical trial results. Between June 2006 and March 2008, 56 patients with metastatic RCC gave informed consent for commencement of sunitinib treatment at our institution. Median age was 61 years (range: 33-78); 68\% had clear-cell histology; $86 \%$ had undergone prior nephrectomy; and $50 \%$ had progressed on IFN- $\alpha$ prior to commencement of sunitinib. Sunitinib was administered orally at a dose of $50 \mathrm{mg}$ once daily, in 6-week cycles consisting of 4 weeks of treatment followed by a 2-week break. All patients were evaluable for toxicity, and 49 for response. The mean dose of sunitinib was $38.15 \mathrm{mg} /$ cycle (range: 25-50); and 402 cycles of sunitinib were delivered. Partial response and stable disease were observed in 41 and $37 \%$ of patients, respectively. Median progression-free survival and overall survival were 12.2 and 18.2 months, respectively. The most common adverse events (all grades) were mucositis (79\%) and fatigue (75\%). Grade 3/4 neutropenia was observed in $13 \%$, and treatmentrelated hypothyroidism in $20 \%$, of patients. Dose-reduction was necessary in $75 \%$ of patients, and $32 \%$ needed hospital admission for treatment-related toxicities. The results from this study confirm the efficacy of sunitinib in the first- and second-line treatment of an unselected group of patients with
\end{abstract}

Correspondence to: Dr J. Ansari, ${ }^{3}$ Present address: Beatson West of Scotland Cancer Centre, 1053 Great Western Road, Glasgow G12 0YN, UK

E-mail: drjawaher@yahoo.com

Key words: sunitinib, metastatic renal cell carcinoma, clear cell, tyrosine kinase inhibitors, targeted agents metastatic RCC. Compared to published data, there was a higher incidence of treatment-related toxicities and a greater necessity for dose-reductions. Despite the increase in toxicity, these results are encouraging and imply that the clinical trial results seen with sunitinib can be translated into routine clinical practice.

\section{Introduction}

Renal cell carcinoma (RCC) is the 11th most common cancer type in the UK, with 7,380 new cases diagnosed in 2005 (1). Approximately $25 \%$ of RCC patients present with either locally advanced (stage III) or metastatic (stage IV) disease (2). Without treatment the prognosis of patients with metastatic renal cell carcinoma (mRCC) is dismal, with a median survival of between 6 and 12 months and a two-year survival of between 10 and $20 \%$ (3). Historically, immunotherapeutic agents such as interleukin-2 (IL-2) and interferon- $\alpha$ (IFN- $\alpha$ ) were the only treatment options available. Despite low response rates $(\sim 15 \%)$, and limited impact on overall survival (OS), cytokines dominated the treatment of $\mathrm{mRCC}$ for nearly two decades $(4,5)$. Treatment with cytokines, particularly IL-2, is associated with significant toxicity, including hypotension, capillary leak syndrome, and central nervous system toxicity, necessitating intensive care admission in many patients. Although complete responses are seen in a small proportion of patients receiving IL-2 therapy, there is considerable treatment-related morbidity and mortality (6-8). There are no randomised trials comparing high-dose IL-2 with less intensive immunotherapeutic approaches.

Recently, a better understanding of the biological mechanisms of carcinogenesis and signal transduction pathways, has transformed the paradigm for the management of mRCC, with the introduction of tyrosine kinase inhibitors. Sunitinib malate is an orally-administered multi-target receptor tyrosine kinase inhibitor (TKI), with anti-proliferative and antiangiogenic properties, targeting the vascular endothelial growth factor receptor types 1-3, platelet-derived growth factor receptors $\alpha$ and $\beta$, FMS-like tyrosine kinase-3, stem cell factor receptor (c-KIT), and RET kinases (9). Two phase II studies $(\mathrm{n}=169)$ demonstrated adequate anti-tumour efficacy (response rate 42\%; median progression-free survival 8.2 months) and a manageable toxicity profile of sunitinib, in patients with cytokine-refractory mRCC (10). A subsequent 
multicenter phase III trial randomised 750 treatment-naïve mRCC patients to either sunitinib (50 mg given orally once daily for four weeks, followed by a two-week break; repeated six-weekly) or IFN- $\alpha$ (9-MU given subcutaneously three times weekly) (11). Treatment with sunitinib was associated with a higher response rate $(31 \%$ versus $6 \%, \mathrm{p}<0.001)$ along with a significant improvement in health-related quality of life $(\mathrm{p}<0.001)$ when compared to IFN- $\alpha$.

Patients in the sunitinib arm had a higher incidence of grade 3 diarrhoea ( $5 \%$ versus $0 \%$ ), vomiting ( $4 \%$ versus $1 \%$ ), hypertension $(8 \%$ versus $1 \%)$ and hand-foot syndrome $(5 \%$ versus $0 \%$ ), whereas treatment-related grade 3-4 fatigue was significantly higher in the IFN- $\alpha$ arm (12\% versus $7 \%)$. Median progression-free survival (PFS) was 11 months in the sunitinib arm, compared to 5 months in the IFN- $\alpha$ arm ( $p<0.001)$. The median OS was 26.4 months in the sunitinib arm and 21.8 months in the IFN- $\alpha$ arm (hazards ratio: $0.821,95 \%$ CI 0.673 to $1.001, \mathrm{p}=0.051)$ (12). Recently published National Institute for Health and Clinical Excellence (NICE) guidance recommends sunitinib as a first-line treatment option for patients with advanced and/or metastatic RCC (13). A recent Canadian population-based study has demonstrated improved outcomes in patients with $\mathrm{mRCC}$ associated with the introduction of sunitinib (14).

This study assesses the impact of treatment with sunitinib in terms of OS, PFS, and toxicity, in an unselected group of patients with $\mathrm{mRCC}$, and assesses the reproducibility of the clinical trial results in routine clinical practice.

\section{Patients and methods}

Between June 2006 and March 2008, 56 patients with mRCC gave informed consent for commencement of sunitinib treatment at our institution (University Hospital Birmingham NHS Trust, Birmingham, UK). Their median age was 61 years (range: 33-78), and 38 patients (68\%) had clear-cell histology. Eighty-six percent of patients had undergone cytoreductive nephrectomy, and $50 \%$ had progressed on IFN- $\alpha$ treatment prior to commencement of sunitinib. Baseline demographic and patient characteristics are described in Table I. Treatmentrelated toxicity, clinical response, PFS, and OS, were analysed. Sunitinib was administered orally once daily in six-week cycles: one cycle comprised four weeks of treatment followed by a two-week break. All patients were assessed on day 1, 14 and 28 for the first two cycles, and thereafter as clinically indicated.

Objective clinical response [complete response, partial response (PR), stable disease (SD), or progressive disease (PD)] was evaluated by Response Evaluation Criteria in Solid Tumours (RECIST) using computed tomography scans. Adverse events and laboratory abnormalities were evaluated using the National Cancer Institute Common Toxicity Criteria (version 3.0) of the National Cancer Institute. Univariate analyses of OS and PFS were undertaken using the KaplanMeier method, with tests of statistical significance performed using the log-rank test and with $95 \%$ confidence intervals constructed using the complementary log-log of the hazard function. OS was measured from date of sunitinib consent, to date of death from any cause; date of death was determined using patient notes and the National Health Service strategic
Table I. Baseline demographics and clinical characteristics.

\begin{tabular}{|c|c|c|}
\hline Characteristics & No. & $\%$ \\
\hline Median age (years) & 61 (range: 33-78) & \\
\hline \multicolumn{3}{|l|}{ Gender } \\
\hline Male & 42 & 75 \\
\hline Female & 14 & 25 \\
\hline \multicolumn{3}{|l|}{ Histology } \\
\hline Clear-cell & 38 & 68 \\
\hline Papillary & 4 & 7 \\
\hline Collecting duct & 1 & 2 \\
\hline Adenocarcinoma & 2 & 3.5 \\
\hline Unclassified & 1 & 2 \\
\hline Translocation carcinoma & 2 & 3.5 \\
\hline Not available & 8 & 14 \\
\hline \multicolumn{3}{|l|}{ ECOG performance status } \\
\hline 0 & 27 & 48 \\
\hline 1 & 19 & 34 \\
\hline 2 & 9 & 16 \\
\hline 3 & 1 & 2 \\
\hline \multicolumn{3}{|l|}{ No. of metastatic sites } \\
\hline 1 & 18 & 30 \\
\hline 2 & 18 & 30 \\
\hline 3 or more & 24 & 40 \\
\hline \multicolumn{3}{|l|}{ Sites of metastatic disease } \\
\hline Liver & 16 & 29 \\
\hline Lung & 35 & 63 \\
\hline Bone & 22 & 39 \\
\hline Adrenal & 6 & 11 \\
\hline Nodes & 25 & 45 \\
\hline Other & 19 & 34 \\
\hline
\end{tabular}

tracking service. PFS was measured from date of sunitinib consent, to the earliest of date of first objective evidence of disease progression or date of death. Estimates of hazard ratios were obtained using the Cox proportional hazards model, with $95 \%$ confidence intervals constructed using the standard error of the regression coefficient. Tests of statistical significance were carried out at the $5 \%$ two-sided significance level.

\section{Results}

Treatment delivery. Four hundred and two cycles of sunitinib were administered to 56 patients. Seven patients (13\%) discontinued treatment within 4 weeks of commencement of first cycle of sunitinib. Forty-two patients $(75 \%)$ required at least one dose-reduction; $13(23 \%)$ required two; and six patients who started treatment at a low dose-level were subsequently dose-escalated by at least one dose-level. The mean dose of sunitinib delivered per cycle was $38.15 \mathrm{mg}$ (range: 25-50). 
Table II. Adverse events and laboratory abnormalities for 56 patients treated with sunitinib.

\begin{tabular}{|c|c|c|}
\hline & $\begin{array}{l}\text { All grades } \\
\text { No. }(\%)\end{array}$ & $\begin{array}{c}\text { Grades } 3 \text { and } 4 \\
\text { No. }(\%)\end{array}$ \\
\hline \multicolumn{3}{|l|}{ Adverse events } \\
\hline Diarrhoea & $25(45)$ & $3(5)$ \\
\hline Fatigue & $42(75)$ & $2(4)$ \\
\hline Nausea & $20(36)$ & 0 \\
\hline Mucositis & $44(79)$ & $12(21)$ \\
\hline Vomiting & $13(23)$ & 0 \\
\hline Hypertension & $17(30)$ & $3(5)$ \\
\hline Hand-foot syndrome & $20(36)$ & $3(5)$ \\
\hline Rash & $8(14)$ & $1(2)$ \\
\hline Dry skin & $2(4)$ & 0 \\
\hline Skin discolouration & $12(21)$ & 0 \\
\hline Hair discolouration & $3(5)$ & 0 \\
\hline Epistaxis & $4(7)$ & 0 \\
\hline Limb pain & $6(11)$ & 0 \\
\hline Headache & $5(9)$ & 0 \\
\hline \multicolumn{3}{|l|}{ Laboratory abnormalities } \\
\hline Anaemia & $51(91)$ & $3(5)$ \\
\hline Leucopenia & $44(79)$ & $8(14)$ \\
\hline Thrombocytopenia & $36(64)$ & $5(9)$ \\
\hline Neutropenia & $36(64)$ & $7(13)$ \\
\hline Increased alkaline phosphatase & $32(57)$ & $3(5)$ \\
\hline Increased bilirubin & $12(21)$ & $1(2)$ \\
\hline Increased aspartate aminotrasferase & $24(43)$ & $1(2)$ \\
\hline Increased creatinine & $35(63)$ & $4(7)$ \\
\hline
\end{tabular}

Toxicity. All patients were included for assessment of toxicity. Percentages relate to the number of patients experiencing the stated toxicity at any point during the treatment period. The most commonly reported adverse events were mucositis (79\%) and fatigue $(75 \%)$. The most frequently occurring laboratory abnormalities were anaemia $(91 \%)$ and leucopenia (79\%). Treatment-related adverse events and laboratory abnormalities are described in Table II. Twenty percent of patients required thyroxine replacement therapy for treatmentrelated hypothyroidism. In total, 18 (32\%) patients required hospital admissions during treatment; four of these admissions were for management of perianal abscesses, and one was for management of a lung abscess.

Efficacy: response rate. Radiological response was evaluable in 49 patients. A PR was observed in 20 patients (41\%), SD in $18(37 \%)$, and PD in 11 patients (22\%). Response could not be assessed in 7 patients due to the following reasons: early treatment-withdrawal due to toxicity $(n=3)$; and death within 6 weeks of commencement of sunitinib $(n=4)$.

PFS and OS. Median PFS and OS for all patients $(\mathrm{n}=56)$ were 12.2 months (95\% CI: 9.0 to 16.0$)$ and 18.2 months (95\% CI: 16.0 to 30.0 ), respectively (Figs. 1 and 2). There was no statistically significant difference in median PFS or OS between patients who received prior immunotherapy $(n=30)$ versus those who did not (treatment naïve group; $n=26$ ).

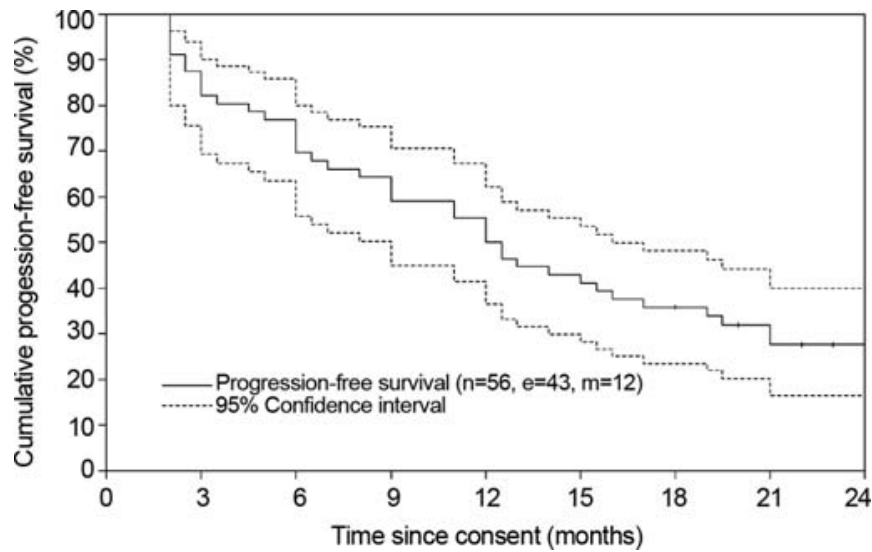

Figure 1. Kaplan-Meier plot of progression-free survival for the 56 patients with $\mathrm{mRCC}$ treated with sunitinib.

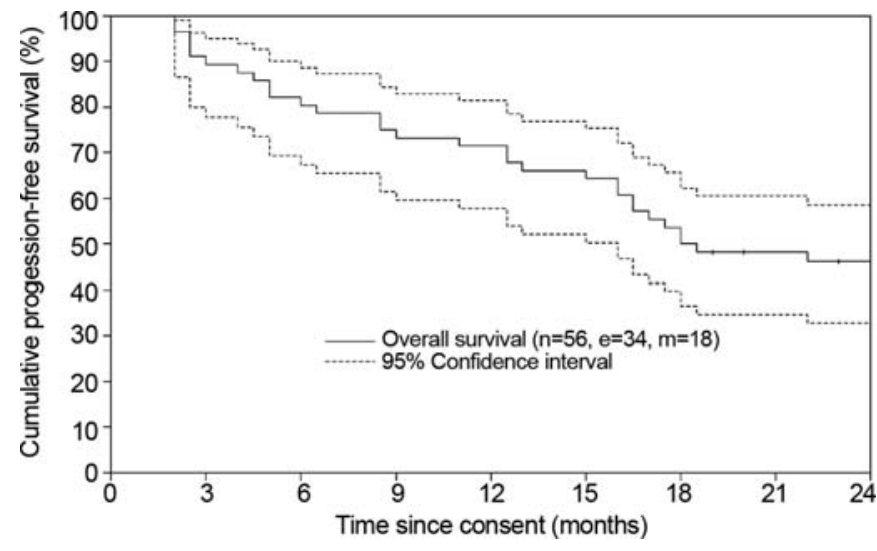

Figure 2. Kaplan-Meier plot of overall survival for the 56 patients with $\mathrm{mRCC}$ treated with sunitinib.

\section{Discussion}

Six molecular targeted agents have so far been approved by the US Food and Drug Administration for the treatment of patients with advanced RCC (sorafenib, sunitinib, pazopanib, bevacizumab combined with IFN- $\alpha$, temsirolimus, and everolimus). So far sunitinib is the only TKI approved by NICE for patients with mRCC. Prior to NICE approval, the usage of sunitinib in the UK had been limited, as the majority of primary care trusts refused to fund this drug. Usage of sunitinib has now increased in the UK, and therefore it is important to know whether the efficacy and survival data seen in clinical trials can be reproduced in day-to-day clinical practice.

Our study demonstrates a PFS of 12.2 months and an OS of 18.2 months in an unselected group of patients with mRCC, which is encouraging. There was no statistically significant difference in PFS or OS between patients receiving sunitinib as first-line treatment or following prior immunotherapy. Compared to published evidence the incidence of mucositis of any grade ( $79 \%$ versus $25 \%$ ), fatigue ( $75 \%$ versus $51 \%$ ) and hand foot syndrome (36\% versus $20 \%$ ) were considerably higher in our study, although the incidence of grade 3 or 4 toxicities was comparable (8). In comparison to other studies, 
a greater percentage of patients in our study required a dosereduction $(75 \%$ vs. $32-35 \%)(8,15)$. As half the patients in this study were being treated in the second-line setting this could have contributed to the increase in toxicity. However, it is interesting to note that in a phase II trial of sunitinib in cytokine-refractory mRCC patients; only $35 \%$ needed a dosereduction. Sunitinib-induced skin toxicity has been reported in several studies, but none of the studies reported any cases of perianal abscesses $(8,16)$.

Patients included in our study represent an unselected group with mRCC and therefore the results demonstrate the reproducibility of clinical trial results in the general population, albeit with a slightly higher toxicity, as may be expected with less stringent patient selection criteria than is typical in the clinical trials setting. Of particular note is the high incidence of hypothyroidism, which we recommend should be monitored carefully in all patients receiving this agent.

In conclusion, the results from this study confirm that the efficacy of sunitinib in the first- and second-line treatment seen in a trial population can be reproduced in an unselected group of patients with mRCC. Compared to published data, there was a higher incidence of treatment-related toxicities, and a greater necessity for dose-reductions. Despite the increase in toxicity, these results are encouraging and imply that the clinical trial results seen with sunitinib can be translated into routine clinical practice.

\section{References}

1. Office for National Statistics: Registrations of cancer diagnosed in 2005, England, 2008.

2. Cohen HT and McGovern FJ: Renal-cell carcinoma. N Engl J Med 353: 2477-2490, 2005.

3. Campbell SC, Flanigan RC and Clark JI: Nephrectomy in metastatic renal cell carcinoma. Curr Treat Options Oncol 4: 363-372, 2003.
4. Wirth MP: Immunotherapy for metastatic renal cell carcinoma. Urol Clin North Am 20: 283-295, 1993.

5. Fisher RI, Rosenberg SA and Fyfe G: Long-term survival update for high-dose recombinant interleukin-2 in patients with renal cell carcinoma. Cancer J Sci Am 6 (Suppl 1): 55-57, 2000.

6. Schwartz RN, Stover L and Dutcher J: Managing toxicities of high-dose interleukin-2. Oncology 16 (Suppl 13): 11-20, 2002.

7. Fyfe G, Fisher RI, Rosenberg SA, Sznol M, Parkinson DR and Louie AC: Results of treatment of 255 patients with metastatic renal cell carcinoma who received high-dose recombinant interleukin-2 therapy. J Clin Oncol 13: 688-696, 1995.

8. Klapper JA, Downey SG, Smith FO, et al: High-dose interleukin-2 for the treatment of metastatic renal cell carcinoma - a retrospective analysis of response and survival in patients treated in the surgery branch at the National Cancer Institute between 1986 and 2006. Cancer 113: 293-301, 2008.

9. Chow LQ and Eckhardt SG: Sunitinib - From rational design to clinical efficacy. J Clin Oncol 25: 884-896, 2007.

10. Motzer RJ, Rini BI, Bukowski RM, et al: Sunitinib in patients with metastatic renal cell carcinoma. JAMA 295: 2516-2524, 2006.

11. Motzer RJ, Hutson TE, Tomczak P, et al: Sunitinib versus interferon alfa in metastatic renal-cell carcinoma. N Engl J Med 356: 115-124, 2007.

12. Motzer RJ, Hutson TE, Tomczak P, et al: Overall survival and updated results for sunitinib compared with interferon alfa in patients with metastatic renal cell carcinoma. J Clin Oncol 27: 3584-3590, 2009.

13. National Institute for Health and Clinical Excellence: Sunitinib for the first-line treatment of advanced and/or metastatic renal cell carcinoma. (Technology appraisal 169). London, NICE, 2009. www.nice.org.uk/TA169.

14. Heng DY, Chi KN, Murray N, et al: A population-based study evaluating the impact of sunitinib on overall survival in the treatment of patients with metastatic renal cell cancer. Cancer 115: 776-783, 2009.

15. Motzer RJ, Michaelson MD, Redman BG, et al: Activity of SU11248, a multitargeted inhibitor of vascular endothelial growth factor receptor and platelet-derived growth factor receptor, in patients with metastatic renal cell carcinoma. J Clin Oncol 24: 16-24, 2006

16. Bhojani N, Jeldres C, Patard JJ, et al: Toxicities associated with the administration of sorafenib, sunitinib, and temsirolimus and their management in patients with metastatic renal cell carcinoma. Eur Urol 53: 917-930, 2008. 